\title{
ANÁLISE DAS INCLUSÓES FLUIDAS DE VEIOS DE QUARTZO EM DEPÓSITOS DE OURO DA PROVÍNCIA DE PORTO NACIONAL (TO)
}

\section{Victor R. C. Schmidt (IC), Maria José M. de Mesquita (PQ), Dailto Silva (PQ)}

\section{Resumo}

O estudo de inclusões fluidas permite entender o modus operandi dos fluidos formadores e/ou modificadores das rochas. Foram analisadas inclusões fluidas da Província de Porto Nacional (TO) de veios de quartzo alojados em filonitos e milonitos. A análise das inclusões sob a ótica da temperatura e fase de homogeneização total e da proporção entre as fases aquosa e carbônica dentro das inclusões permite 0 cálculo da densidade do fluido e da proporção molar entre as diferentes porções da inclusão. Deste modo, os dados levantados contribuem para o desenvolvimento de modelos metalogenético para a área.

Palavras Chave: inclusões fluidas, metalogênese, microtermometria

\section{Introducão}

Inclusões fluidas são inclusões de fluido que se encontra em estado líquido e/ou gasoso no momento em que é aprisionado por um mineral. Esse aprisionamento se dá durante a cristalização dos minerais hospedeiros ou durante posterior deformação (Roedder, 1984).

Entender se no processo mineralizador ocorreu mistura de fluidos ou efervescência de um mesmo fluido é fundamental para compreender como se deu a precipitação de metais. Desse modo, o estudo das inclusões fluidas pode contribuir com o desenvolvimento de modelos metalogenéticos.

A área estudada é o depósito de ouro tipo veio da Província de Porto Nacional, Tocantins, e o foco da pesquisa é a metodologia de análise de inclusão fluida nos veios de quartzo.

\section{Resultados e Discussão}

A área de estudo é caracterizada por terrenos de granitos e gnaisses de fácies granulito afetados por zonas de cisalhamento transcorrente de caráter dúctil a rúptil-dúctil (Mesquita, 1996). Faixas de filonitos e milonitos alojam veios de quartos mineralizados a ouro. O veio estudado apresenta três assembleias de inclusões fluidas diferentes ( $F I A s)$, conforme a existência de fase aquosa, carbônica, e as proporções entre estas em temperatura ambiente (Mesquita 1996): inclusões carbono-aquosas (CA), inclusões aquocarbônicas (AC) e inclusões aquosas (A).

A proporção entre as fases aquosas e carbônicas de cada uma das 64 inclusões estudadas foi obtida por meio do uso do programa AutoCAD 2014 (Figura 1). A fase carbônica varia entre 0,2 e 0,72 na CA FIA e entre 0,04 e 0,5 na AC FIA. Por meio de cada uma dessas proporções podese calcular a densidade de cada fluido trapeado. Essa distribuição heterogênea dos dados de ambas as FIAs pode indicar que os fluidos estudados podem ser misturas de fluidos distintos em proporções diversas ou podem ter sido modificados após aprisionados (Roedder, 1984). Uma análise das microestruturas e dados composicionais ou de isótopos desse fluido são necessários para confirmar tais hipóteses.

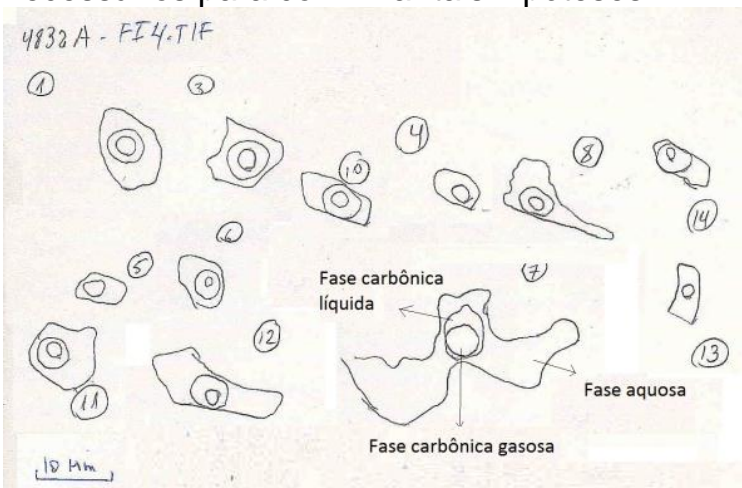

Figura 1 Desenho obtido em câmara clara (Mesquita, 1996) com inclusões do tipo AC. Na amostra 4832A, a fase carbônica variou entre $9 \%$ e $49 \%$.

A temperatura de homogeneização total $\left(T_{h}\right)$ foi obtida via técnica de microtermometria em platina de aquecimento LINKAM THMSG600 adaptada a um microscópio petrográfico LEIKA convencional, no Laboratório de Microtermometria do IGUNICAMP. Obteve-se para a AC FIA $290,5 \pm 36,1^{\circ} \mathrm{C}$ e para a A FIA $232,3 \pm 15,0{ }^{\circ} \mathrm{C}$ com homogeneização total para a fase líquida nos dois casos. Além disso, sabe-se que cada fluido se encontrava, no mínimo, na temperatura de homogeneização total medida (Mesquita, 1996).

\section{Conclusões}

A distribuição heterogênea dos dados obtidos pode indicar processos de mistura de fluidos de origens distintas ou, alternativamente, modificação do fluido após seu aprisionamento por deformação.

Os resultados da $T_{h}$ indicam que os diferentes fluidos se encontravam, no mínimo, nessas temperaturas antes de serem aprisionados.

\section{Agradecimentos}

Agradeço aos meus orientadores Maria José Maluf de Mesquita e Dailto Silva por todo o apoio acadêmico prestado e ao suporte do CNPq (processo 119331/2014-4).

Roedder, E., 1984. Fluid Inclusions, Mineralogical Society of America, Reviews in Mineralogy, v. 12, 664p.

Mesquita, M.J., 1996. Alteração metamórfico-hidrotermal nos depositos de ouro da Província de Porto Nacional, TO - Brasil. Tese (Doutorado), IG-UFRGS 